\title{
Study on the Influence of Reservoir Dispatch of the Upper Yangtze River on the Runoff Control
}

\author{
Tang Bing ${ }^{1, *}$, Wang WenChao ${ }^{1}$, and Fan Xiaozhi ${ }^{1}$ \\ ${ }^{1}$ Changjiang Institute of Survey, Planning, Design and Research, Wuhan, Hubei, China
}

\begin{abstract}
The reservoir group focusing on the Three Georges reservoir has been established in the upper Yangtze River, with a total regulation capacity of 51.5 billion $\mathrm{m} 3$. The reservoir group dispatch plays an important role in regulating the runoff. Economic activity in the Yangtze River estuary poses high requirements for water resources security. The water quality of main water supply reservoirs is influenced by the saltwater intrusion. The upstream reservoir group dispatch can enhance sea inlet runoff and mitigate saltwater intrusion hazard. In order to clarify the upstream reservoir group's influence on the sea inlet water quantity in the Yangtze River estuary, the author designed three typical reservoir group dispatch scenarios to analyze flow rate change and different dispatch scenarios of Datong section. According to the findings, the upstream reservoir group dispatch is important to secure water quantity in the dry season. Through normal dispatch, the Three Georges reservoir can cut the days with a flow rate less than 100 million m3/s from 50.6 days to 8.8 days. In the special dry year, the sole emergency water supplement by the Yangtze River reservoir to the estuary will exert influence on the reservoir power generation. The joint operation of upstream reservoir group can basically eliminate such influence.
\end{abstract}

\section{Introduction}

Saltwater intrusion is the biggest factor restricting the development and utilization of fresh water resources in the Yangtze River estuary. The Yangtze River estuary has abundant water of good quality basically reaching class standard of surface water. The yearly average per capital sea runoff flow rate was nearly 900 billion $\mathrm{m} 3$. However, when the upstream discharge is less, it's unable to get the qualified source water because of saltwater intrusion and chlorine content in the headwaters taking port beyond the standard, especially in the super dry season when the saltwater intrusion duration exceeds the headwaters supply capability [1].

The upstream runoff and the outer sea tide strength are the two determinant factors for saltwater invasion of the Yangtze River estuary. The established group of reservoirs in the upper Yangtze River has a total regulatory capacity of 51.5 billion $\mathrm{m} 3$, making it likely to regulate sea inlet runoff. Because of reciprocal flow, it's quite difficult to measure the flow of Xuliujing section, which is quite correlated to Datong section [2]. With Datong Hydrology Station as the objective, the author studies the influence of the joint operation of upstream reservoirs group focusing on the Three Georges reservoir and seal inlet runoff of the Yangtze River estuary, providing a basis for water quantity distribution.

\section{Materials and Methods}

\subsection{Study area profile}

The author studies the control reservoir to be put in operation in 2020 and having bigger influence on the water resources dispatch in the middle and lower Yangtze River. The study covers 23 reservoirs, including Liyuan, Ahai, Jinanqiao, Longkaikou, Ludila and Guanyinyan in the middle Jinsha River, Xiluodu and Xiangjiaba in the lower Jinsha River, Jinpingyiji and Ertan in the Yalong River, Pubugou and Zipingpu in the Min River (including the branch Dadu River), Baozhusi, Tingzikou and Caojie of the Jialing River (including the branch Bailong River), Hongjiadu, Dongfeng, Wujiangdu, Goupitan, Silin, Shatuo and Pengshui in the Wu River and Three Georges in the Yangtze River. The upstream cascading reservoirs have a total regulation capacity of 51.35 billion $\mathrm{m} 3$, a total flood control capacity of 36.379 billion $\mathrm{m} 3$, and the total installed power generation capacity of 79,495 MW.

\subsection{Dispatch method}

According to the Yangtze River comprehensive utilization, flood control planning and the design results in the Yangtze River Basin, the overall arrangement of the main and branch control reservoirs serviceable in 2020 in the upper Yangtze River: The reservoir should follow the flood control requirements in the rainy season,

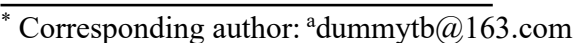


accumulate water while ensuring flood control safety; after the flood, guarantee the minimum discharge and dispatch basically upon power generation need.

Table 1 Water quantity dispatch reservoir characteristics

\begin{tabular}{|c|c|c|}
\hline River & $\begin{array}{c}\text { Cascade reservoir } \\
\text { name }\end{array}$ & $\begin{array}{c}\text { Regulation } \\
\text { capacity (100 } \\
\text { million m3) }\end{array}$ \\
\hline \multirow{6}{*}{$\begin{array}{c}\text { Middle } \\
\text { Jinsha River }\end{array}$} & Liyuan & 0.83 \\
\hline & Ahai & 2.15 \\
\hline & Jinanqiao & 3.46 \\
\hline & Longkaikou & 1.13 \\
\hline & Ludila & 3.76 \\
\hline & Guanyinyan & 5.55 \\
\hline \multirow{2}{*}{$\begin{array}{l}\text { Yalong } \\
\text { River }\end{array}$} & Jinpingyiji & 49.10 \\
\hline & Ertan & 33.70 \\
\hline \multirow{2}{*}{$\begin{array}{l}\text { Lower Jinsha } \\
\text { River }\end{array}$} & Xiluodu & 64.60 \\
\hline & Xiangjiaba & 9.03 \\
\hline Min River & Zipingpu & 7.74 \\
\hline Dadu River & Pubugou & 38.82 \\
\hline $\begin{array}{l}\text { Bailong } \\
\text { River }\end{array}$ & Baozhusi & 13.40 \\
\hline \multirow{2}{*}{ Jialing River } & Tingzikou & 17.50 \\
\hline & Caojie & 4.87 \\
\hline \multirow{7}{*}{ Wu River } & Hongjiadu & 33.61 \\
\hline & Dongfeng & 4.91 \\
\hline & Wujiangdu & 13.60 \\
\hline & Goupitan & 29.52 \\
\hline & Silin & 3.17 \\
\hline & Shatuo & 2.87 \\
\hline & Pengshui & 5.18 \\
\hline $\begin{array}{l}\text { Yangtze } \\
\text { River }\end{array}$ & Three Georges & 165.00 \\
\hline Total & & 513.50 \\
\hline
\end{tabular}

\subsection{Dispatch objectives}

\subsubsection{Target fracture}

Datong Station is an important control station in the lower Yangtze River. Its flow rate determines the strength and distance of the saltwater upward movement in the Yangtze River estuary. Datong Hydrology Station (the lowest reach of main Yangtze River), $\sim 500 \mathrm{~km}$ from the estuary (Xuliujing), and belonging to the tide area boundaries of the outer sea. In 1923, the Station began to have flow rate observation information. In 1951, it began to have complete water and sand observation information. Datong Station had an average annual average flow rate of $28,300 \mathrm{~m}^{3} / \mathrm{s}$ and an average annual average runoff flow rate of $8,940 \mathrm{~m}^{3}(1950 \sim 2009)$. The annual water was concentrated in May October, accounting for $70.5 \%$ of the yearly total. The supply water volume from November to the following April accounted for $29.5 \%$ of the yearly total. The monthly average flow rate over years was biggest in July and smallest in January.

\subsubsection{Target flow}

The previous studies proposed to call the flow rate of Datong Hydrology Station without estuary saltwater intrusion the critical flow rate. Rather than a constant value [4], the existing studies proposed that the flow rate of $10000 \sim 13000 \mathrm{~m}^{3} / \mathrm{s}$ could make the Yangtze River estuary headwaters basically immune to saltwater influence. According to the actual measurement data in dry seasons from 2003 to 2007, Chenhang headwaters was influenced by saltwater intrusion 32 times. Among these saltwater intrusion events, there were 20 times when the runoff flow rate of Datong Hydrology Station was over $13000 \mathrm{~m}^{3} / \mathrm{s}$, and 14 times when the runoff flow rate was over $15,000 \mathrm{~m}^{3} / \mathrm{s}$.

According to the current construction study results in the Yangtze River estuary [5], and the statistics of days with a small rate (see Table 2), Datong flow rate of 10,000 $\mathrm{m}^{3} / \mathrm{s}$ might greatly alleviate saltwater hazard even if it couldn't thoroughly eliminate the problem of saltwater intrusion, which still might be the basic objective of the joint operation of upstream reservoir group. In case of saltwater intrusion when the Datong flow rate was above $10,000 \mathrm{~m}^{3} / \mathrm{s}$, seek solution by enhancing water resources dispatch and management in the middle and lower Yangtze River. Therefore, the critical flow rate was defined as $10,000 \mathrm{~m}^{3} / \mathrm{s}$.

Table 2 Days with small flow rate in Datong Hydrology Station under natural conditions

\begin{tabular}{|c|c|c|c|}
\hline $\begin{array}{c}\text { Datong } \\
\text { Hydrology } \\
\text { Station }\end{array}$ & $\begin{array}{c}\text { Days less } \\
\text { than } 8,000 \\
\mathrm{~m}^{3} / \mathrm{s}\end{array}$ & $\begin{array}{c}\text { Days less } \\
\text { than } 10,000 \\
\mathrm{~m}^{3} / \mathrm{s}\end{array}$ & $\begin{array}{c}\text { Days less } \\
\text { than } 12,000 \\
\mathrm{~m}^{3} / \mathrm{s}\end{array}$ \\
\hline Jan & 167 & 792 & 1206 \\
\hline Feb & 171 & 598 & 938 \\
\hline Mar & 55 & 270 & 437 \\
\hline Apr & 0 & 21 & 47 \\
\hline May Oct & 0 & 0 & 0 \\
\hline Nov & 0 & 0 & 21 \\
\hline Dec & 23 & 218 & 537 \\
\hline
\end{tabular}

\subsection{Calculation scheme}

The upstream reservoir group dispatch focuses on the Three Gorges reservoir, and its dispatch has a huge influence on the Yangtze River area. After the water accumulation in 2003, higher requirements for the Three Gorges reservoir dispatch had been put forward in terms of safeguarding ecological environment and water supply safety for the middle and lower reaches, enhancing comprehensive utilization benefits of the Three Gorges, especially power generation gains. When the Three Gorges reservoir reached $175 \mathrm{~m}$ in 2009, it would be responsible for comprehensive utilization. To give full play to the comprehensive utilization benefits of the Three Gorges and provide technical support for the preparation of the Three Gorges reservoir normal operation procedure, the author conducts an optimal study on the current reservoir dispatch method. 


\subsubsection{Sole operation of the Three Gorges Reservoir}

During an optimal study on the Three Georges reservoir dispatch scheme, the author comprehensively considers the influence of the Three Georges reservoir water accumulation on the middle and lower Yangtze River. While giving full play to the Three Georges reservoir's flood control, power generation and shipping efficiency, we should attempt to effectively regulate water accumulation and discharge, and coordinate water supply and ecological safety in the dry and rainy season. Besides, the author has put forward normal dispatch scheme, reservoir flood end dispatch scheme; emergency dispatch scheme, water resources and ecology dispatch scheme in dry seasons.

(1) Reservoir flood end water accumulation dispatch scheme

In order to display the established comprehensive utilization benefits, it is of utmost importance to complete flood end water accumulation. The task of water accumulation is arduous as the Three Georges reservoir capacity after flood reaches 22.15 billion $\mathrm{m}^{3}$ from the normal water level of $175 \mathrm{~m}$. According to the preliminary design scheme, the water accumulation starts on October 1 when the rainy water level is $145 \mathrm{~m}$. During water accumulation period, the minimum discharge flow rate should not be lower than the flow rate of the guaranteed output. In general, the water accumulation reaches normal water level of $175 \mathrm{~m}$ at the end of October. When the supply water is good in middle and late September, properly extend the water accumulation duration to guarantee desired discharge and better coordinate reservoir flood end water accumulation and downstream water use. At the meantime, it improves the reservoir full accumulation guarantee and plays a positive role for downstream water use and alleviate saltwater intrusion in dry seasons.

The earlier water accumulation scheme for the Three Gorges reservoir put forward herein won't have an adverse influence on flood control safety and exerts small effect on silt sedimentation in the reservoir area. It can also increase the annual average power generation of 1266 million $\mathrm{kW} \cdot \mathrm{h}$ and make the flow rate changes during the water accumulation period close to the natural state. Uniform change of the outlet flow rate is conducive to a reasonable arrangement of power supply plan and guaranteeing power supply safety.

(2) After the Three Gorges Reservoir water accumulation is $175 \mathrm{~m}$, the reservoir capacity regulation is 16.5 billion $\mathrm{m}^{3}$. According to the initial design, in order to facilitate power generation and reservoir shipping in dry seasons, the power station generally generates power at the guarantee output of 4.99 million $\mathrm{kW}$. The reservoir should maintain a high water level as much as possible. When the supply water flow rate cannot provide the guarantee output, supplement water by the reservoir. In light of the power generation and shipping need, gradually reduce the reservoir water level to the low threshold of $155 \mathrm{~m}$.

When the reservoir water level reduces from $175 \mathrm{~m}$ to $155 \mathrm{~m}$, conduct estuary saltwater suppression and Dongting Lake water supplement generally at the beginning of the year. Choose this time period to set the minimum discharge volume or the compensation mode when the reservoir water level is at the lower limit. Properly increase the discharge volume of the Three Georges reservoir to meet the downstream needs. In the super dry season, apply the dispatch principle when the reservoir water level is below $155 \mathrm{~m}$ or take the emergency dispatch measures in case of drought disaster or major water pollution incidents in the Three Gorges reservoir area and downstream rivers.

\subsubsection{Joint dispatch of upstream reservoir group}

When a batch of comprehensive water conservancy hubs are put in operation in the Yangtze River, it puts forward practical requirements for the comprehensive dispatch and utilization of the Yangtze River main and branch cascading reservoir group. In order to consolidate water resources comprehensive utilization and protection, coordinate correlations of flood control, power generation, shipping, water supply, ecology and environmental protection and give full play to the reservoir's comprehensive utilization benefits and flood control, we can increase the flood control capacity of the Three Georges reservoir for Chenglingji from 5.65 billion $\mathrm{m}^{3}$ to $\sim 10$ billion $\mathrm{m}^{3}$. When Chenglingji encounters a flood once a hundred years, the downstream flood diversion volume can be further reduced by $\sim 7.4$ billion $\mathrm{m}^{3}$; reduce the discarded water so that the water energy resources for power generation in the Yangtze River can be more reasonably utilized; with respect to shipping and water supply, the joint operation of reservoir group can increase the flow rate of $\sim 2,000 \mathrm{~m}^{3} / \mathrm{s}$ in dry seasons, and improve shipping and water supply in the middle and lower Yangtze River. In terms of ecology and environmental protection, the flow rate of the river above the Three Gorges reservoir increases, significantly improving the water environment in the Jialing River estuary and Jinsha River estuary, and helping to somewhat inhibit "algal blooms" in the Wujiang River estuary. From December to the following May in the dry season, Datong flow rate increases over the single reservoir dispatch, favorable for alleviating influence on the important drinking headwaters by the Yangtze River estuary saltwater intrusion. Besides, it can increase the reservoir full level rate. Compared to scattered dispatch, the Three Georges reservoir full level rate in October can increase by $\sim 95$. The discharge also increases by $\sim 1000 \mathrm{~m}^{3} / \mathrm{s}$ over the scheme.

When the Yangtze River or a certain branch comes across super dry season, the upstream cascading reservoirs should be combined to increase water supply so that the lower rivers' main control fractures can guarantee water supply. If necessary, the power generation benefits can be compromised; first use the multi-year regulation reservoir, and step up power station output according to the reservoir regulation capacity to increase the discharge volume. If necessary, it's possible to drop some reservoirs below the dead water level. The author starts from the Three Gorges reservoir's water supplement to the middle and lower Yangtze River in dry seasons and move to the 
study of downstream water supply by branch reservoirs combined with the Three Gorges reservoir. When the middle and lower Yangtze River encounters super dry season, the upstream reservoirs and the Three Gorges reservoir should enlarge discharge to compensate the middle and lower water supply. If necessary, the Three Gorges reservoir may start capacity regulation below 155 $\mathrm{m}$ in advance to further mitigate the middle and lower water supply pressure.

\section{Results \& Discussion}

\subsection{Normal dispatch's influence on estuary water quantity}

During the Three Gorges reservoir's normal dispatch, before the construction of and after water accumulation of the Three Gorges reservoir, and in $1951 \sim 2002$ before water accumulation of the Three Gorges reservoir, the multi-year average number of days is respectively $8 \mathrm{~d}$, $36.6 \mathrm{~d}$ and $61.2 \mathrm{~d}$ when Datong's daily average flow rate is less than $8,000 \mathrm{~m}^{3} / \mathrm{s}, 10,000 \mathrm{~m}^{3} / \mathrm{s}$ and $12,000 \mathrm{~m}^{3} / \mathrm{s}$, and the multi-year average number of days is respectively $6 \mathrm{~d}$, $29.2 \mathrm{~d}$ and $47.5 \mathrm{~d}$ when the flow rate is continuously less than $8,000 \mathrm{~m}^{3} / \mathrm{s}, 10,000 \mathrm{~m}^{3} / \mathrm{s}$ and $12,000 \mathrm{~m}^{3} / \mathrm{s}$. In $2003 \sim$ 2007 after Three Gorges reservoir water accumulation, the days and continuous occurrence days somewhat reduce because of the Three Gorges reservoir accumulation regulation.

Table 3 Influence of the Three Gorges reservoir's normal dispatch on days of small flow rate of the lower estuary

\begin{tabular}{|c|c|c|}
\hline Statistics years & $1951-2002$ & $2003-2007$ \\
\hline $\begin{array}{c}\text { Days with flow rate } \\
<8,000 \mathrm{~m} 3 / \mathrm{s}\end{array}$ & 8 & 0 \\
\hline $\begin{array}{c}\text { Days with flow rate } \\
\text { continuously }<8000 \\
\text { m3/s }\end{array}$ & 6 & 0 \\
\hline $\begin{array}{c}\text { Days with flow } \\
\text { rate }<10,000 \mathrm{~m} 3 / \mathrm{s}\end{array}$ & 36.6 & 8.8 \\
\hline $\begin{array}{c}\text { Days with flow rate } \\
\text { continuously }<10,000 \\
\text { m3/s }\end{array}$ & 29.2 & 49.8 \\
\hline $\begin{array}{c}\text { Days with flow } \\
\text { rate }<12,000 \text { m3/s }\end{array}$ & 61.2 & 35.4 \\
\hline $\begin{array}{c}\text { Days with flow rate } \\
\text { continuously }<12,000 \\
\text { m3/s }\end{array}$ & 47.5 & 90.2 \\
\hline $\begin{array}{c}\text { Days with flow } \\
\text { rate }<15,000 \text { m3/s }\end{array}$ & 93.9 & 55.8 \\
\hline $\begin{array}{c}\text { Days with flow rate } \\
\text { continuously }<15,000 \\
\text { m3/s }\end{array}$ & 66.7 & 8.8 \\
\hline
\end{tabular}

\subsection{Ecological dispatch's influence on the estuary water quantity}

The Three Gorges adopts ecological dispatch to ensure that Yichang fracture's flow rate is not less than $8,000 \mathrm{~m}^{3}$, and Datong fracture will never have the small flow $<10,000 \mathrm{~m}^{3} / \mathrm{s}$. Analysis results for $1959-1960$ are given in table 4. For dry years, emergency water supply in early January exerted the biggest influence on the Three Georges reservoir, caused by difference of actual water supplement quantity and power generation water head in different years and time intervals. In general, for most dry years, if the Three Gorges reservoir supplements on its own, emergency dispatch will have a certain impact on the power generation benefits and shipping of the Three Gorges reservoir.

Table 4 Ecological dispatch's influence on Three Georges power generation

\begin{tabular}{|c|c|c|c|c|c|c|}
\hline Years & $\begin{array}{c}\text { Emergency } \\
\text { dispatch } \\
\text { time }\end{array}$ & $\begin{array}{c}\text { Electricity } \\
(100 \mathrm{~m} \\
\mathrm{kW} \cdot \mathrm{h})\end{array}$ & $\begin{array}{c}\text { Dec } \sim \text { May } \\
\text { electricity } \\
(100 \mathrm{~m} \\
\mathrm{kW} \cdot \mathrm{h})\end{array}$ & $\begin{array}{c}\text { Output } \\
\text { destruction } \\
\text { days (days) }\end{array}$ & $\begin{array}{c}\text { Days with } \\
\text { reservoir water } \\
\text { level lower than } \\
164 \mathrm{~m} \text { (days) }\end{array}$ & $\begin{array}{c}\text { Days with } \\
\text { reservoir water } \\
\text { level lower than } \\
155 \mathrm{~m} \text { (days) }\end{array}$ \\
\hline \multirow{5}{*}{$1959 \sim 1960$} & Normal dispatch & 696.06 & 248.19 & 6 & 289 & 149 \\
\cline { 2 - 7 } & Early December & 694.57 & 246.7 & 18 & 295 & 149 \\
\cline { 2 - 7 } & Early January & 693.41 & 245.55 & 40 & 305 & 149 \\
\cline { 2 - 7 } & Early February & 694.5 & 246.63 & 31 & 289 & 151 \\
\hline
\end{tabular}

\subsection{Comparison to calculation result of traditional method}

For most dry years, if the Three Gorges reservoir supplements on its own, emergency dispatch will have a certain impact on the power generation benefits and shipping of the Three Gorges reservoir. Therefore, it's possible to consider joint water supplement of the upstream main and branch control reservoirs to reduce adverse influence on comprehensive utilization requirements in the Three Gorges reservoir. The water supplement quantity will be shared according to the actual water accumulation ratio of reservoir before emergency dispatch to increase discharge quantity during emergency dispatch period. The schemes' influence on main indicators of the Three Georges in dry seasons is given in Table 5. 


\section{Conclusions}

(1) The operation of upstream reservoirs further enhances the water accumulation regulation capacity. Proper increment of minimum discharge in dry seasons will further lessen water supply safety threat in the Yangtze River estuary by saltwater intrusion; in case of severe saltwater intrusion in the Yangtze River estuary

Table 5 Joint operation of upstream reservoir group's influence on Three Georges power generation

\begin{tabular}{|c|c|c|c|c|c|c|}
\hline \multirow{2}{*}{ Years } & $\begin{array}{c}\text { Emergency dispatch } \\
\text { time }\end{array}$ & $\begin{array}{c}\text { Electricity } \\
(100 \mathrm{~m} \mathrm{~kW} \cdot \mathrm{h})\end{array}$ & $\begin{array}{c}\text { Dec } \sim \text { May } \\
\text { electricity }(100 \\
\mathrm{m} \mathrm{kW} \cdot \mathrm{h})\end{array}$ & $\begin{array}{c}\text { Output } \\
\text { destruction } \\
\text { days (days) }\end{array}$ & $\begin{array}{c}\text { Days with } \\
\text { reservoir water } \\
\text { level lower } \\
\text { than } 164 \mathrm{~m} \\
\text { (days) }\end{array}$ & $\begin{array}{c}\text { Days with } \\
\text { reservoir water } \\
\text { level lower } \\
\text { than } 155 \mathrm{~m} \\
(\text { days })\end{array}$ \\
\hline \multirow{3}{*}{$1959 \sim 1960$} & Normal dispatch & 696.06 & 248.19 & 6 & 289 & 149 \\
\cline { 2 - 7 } & Early December & 695.97 & 248.10 & 10 & 292 & 149 \\
\cline { 2 - 7 } & Early January & 696.99 & 249.12 & 12 & 293 & 149 \\
\cline { 2 - 7 } & Early February & 697.02 & 249.15 & 9 & 289 & 150 \\
\hline
\end{tabular}

(2) Normal water supplement dispatch: In the ordinary year, if the Three Gorges reservoir only regulate the minimum discharge to $6,000 \mathrm{~m}^{3} / \mathrm{s}$ in December and March, the minimum discharge of other reservoirs may not be adjusted because of limited influence and water supplement increment. If the regulation scheme with bigger water supplement quantity is adopted, the minimum discharge of other control reservoirs should be adjusted accordingly by increasing the discharge from December to the following March in light of the water quantity increment and actual water accumulation capacity.

(3) Emergency dispatch: The Three Gorges reservoir will compensate the discharge according to the threshold of $10000 \mathrm{~m}^{3} / \mathrm{s}$ of Datong Station. It is necessary to determine the Three Gorges reservoir's increased discharge and duration according to the discharge transfer time, Datong Station's forecast flow and Yangtze River estuary's salinity indicators. Besides, it is also necessary to reserve a certain leeway when determining the discharge increment, and arrange the additional discharge of other control reservoirs based on their distance with the Yangtze River reservoir from far to near and the reservoir's actual water accumulation quantity from big to small (deduct the portion of the Yangtze River reservoir). Discharge should be increased during emergency dispatch. The reservoir's added discharge should be the sum of additional discharge of the upstream control reservoirs.

(4) In order to mitigate influence on other comprehensive utilization tasks and facilitate management, it's recommended to propose a proper water level for Three Gorges Reservoir to start the upstream reservoir water supplement. Other upstream reservoirs should begin water supplement when the Three Gorges reservoir water level is below the line.

\section{Acknowledgments}

This paper is one of the phased achievements of The National Key Research and Development Project -Technology and Application of Water Resources and salt suppression by fresh water, the upstream reservoirs can take emergency dispatch measures to increase the discharge volume. The water quantity increment because of normal dispatch and emergency dispatch should be shared by the upstream reservoirs in principle and allocated according to the reservoir regulation capacity or water accumulation volume.
Dispatching for Complex River-lake-connected Areas in the Yangtze River Delta (2016YFC0401506).

\section{References}

1. Chen qinjiang, $\mathrm{Xu}$ jiangyi, Determination and measures of salt tide control critical flow in Yangtze estuary headwaters.J. Yangtze River. 42(18): 68-72 (2011)

2. Tang Jianhua, Liu Weiyi, Zhao shengwe. Discussion on the relationship between Xuliujing discharge and Datong discharge in the Changjiang Estuary .J. Water Resources and Power, 29(07):4-7(2011)

3. GAO Hua-bin, TANG Bing, Empirical Model of Critical Flow Rate in Response to Salt Water Intrusion in the Yangtze River Estuary.J. Journal of Yangtze River Scientific Research Institute. 37(4): 25-29. (2020)

4. He Shaokun, Guo Shenglian, Liu Pan. Joint and optimal impoundment oepration of Jinsha River's cascade reservoirs and Three Gorges Reservoir. J. Journal of Hydroelectric Engineering.38(8):2736(2019)

5. Wang Wei. The Research on the Influence of the Change of River Discharge at Datong on the Saltwater Intrusion in Yangtze Estuary. J. Science Technology and Engineering. 3:106-111. (2016) 